\title{
Testicular Cancer by AJCC v6 and v7 Stage
}

National Cancer Institute

\section{Source}

National Cancer Institute. Testicular Cancer by A/CC v6 and v7 Stage. NCI Thesaurus.

Code C140241.

A term that refers to the staging of testicular cancer according to the American Joint Committee on Cancer, 6th and 7th editions. 